\title{
IGUALDADE DE GÊNERO NAS RELAÇÕES DE TRABALHO: SUPERANDO OS ESTEREÓTIPOS ENTRE HOMEM E MULHER
}

\author{
Maycon Samuel Xavier Pereira ${ }^{1}$ \\ Marcelo Loeblein dos Santos ${ }^{2}$
}

\begin{abstract}
RESUMO: A presente pesquisa aborda o hodierno desafio da busca por igualdade nas relações de gênero, versando sobre a ótica da legislação e da doutrina brasileira, visando à proteção da mulher trabalhadora e a inclusão feminina no mercado de trabalho. Estuda as limitações impostas pelo ordenamento jurídico no que tange a edição de normas sem qualquer conotação legal, evitando assim os abusos e arbitrariedade, compara os números de pesquisas de emprego do Governo Federal identificando as deficiências na inclusão da mulher no mercado de trabalho buscando esclarecer os fatores que levam a existência dos estereótipos nas relações trabalhistas. Trata com ênfase o Art. $5^{\circ}$, inciso I da Constituição Federal de 1988, questiona o Art. $7^{\circ}$ incisos XX e XXX, e estuda as Leis $n^{\circ}$. 9.029/95 e 9.799/99, que acentuam o combate a discriminação do trabalho feminino. Conclui a pesquisa abordando as principais proteções legais ao trabalho da mulher.

PALAVRAS-CHAVE: Igualdade nas Relações de Gênero, Mercado de Trabalho da Mulher, Constituição Federal.
\end{abstract}

\section{GENDER EQUALITY IN WORKING RELATIONSHIPS: OVERCOMING THE STEREOTYPES BETWEEN MAN AND WOMAN}

\begin{abstract}
This research approaches the today challenge of the search for equality in gender relations, focusing on the perspective of legislation and of the Brazilian doctrine, aiming to the protection of working women and their inclusion in the labor market. Considers the limitations imposed by the law on the edition of standards without any connotation lawful, thus avoiding the abuse and arbitrariness, compares the numbers of research of employment of the Federal Government identifying the shortcomings in the inclusion of women in the labor market seeking enlighten the factors that lead the existence of stereotypes labor relations. Addresses the Article 5, item I of the Federal Constitution of 1988, it questions the Article 7 items XX and XXX, and studies the Laws number 9.029/95 and 9.799/99, which underline the combat discrimination of the feminine work. Concludes the research addressing the main legal protections of the work of women.

KEY-WORDS: Equality in Gender Relations, the Labor Market of Women, Federal Constitution.
\end{abstract}

\section{Introdução}

A Constituição Federal de 1988 positivou no ordenamento jurídico brasileiro um Título que trata em especial sobre os direitos e garantias fundamentais, no qual a doutrina moderna apresenta uma classificação de direitos fundamentais de primeira, segunda e terceira e quarta gerações. Assim, com base numa ordem histórica cronológica, passaram a ser constitucionalmente reconhecidos, sendo que os direitos a serem abordados nesse estudo são os chamados de segunda geração, que conforme dita o Ministro Celso de Mello (1995), são os quais definem o Princípio da Igualdade, embasado nas liberdades positivadas, reais ou concretas.

\footnotetext{
1 Acadêmico graduando do sétimo período do Curso de Direito do IFPR - Instituto Federal no Paraná, Campus Palmas.

2 Professor Orientador. Graduado em Letras e Direito pela UNIJUÍ - Universidade Regional do Noroeste do Estado do Rio Grande do Sul. Mestre em Direito pela UCS - Universidade de Caxias do Sul. Professor da FAI - Faculdades de Itapiranga.
} 
Neste liame, vale destacar que o Brasil como Estado Democrático de Direito, busca minimizar as desigualdades, em prevalência ao Princípio da Dignidade da Pessoa Humana, elencado no seu Art. $1^{\circ}$, inciso III, e o Princípio da Igualdade, ou isonomia, proclamado no seu Art. $5^{\circ}$. Caput, o qual aduz: "Todos são iguais perante a lei, sem distinção de qualquer natureza $[\ldots]]^{3}$.

Apesar da redução da desigualdade de gênero, inclusive com promulgação da Lei Federal $\mathrm{n}^{\circ}$ 9.799, de 26 de maio de 1999 que trata singularmente sobre o acesso da mulher ao mercado de trabalho, e de programas próprios do Governo Federal, inclusive com a criação em 2003, da Secretaria Especial de Políticas para as Mulheres - SPM, a qual integra o Conselho Nacional dos Direitos da Mulher - CNDM, é fato que as mulheres encontram dificuldades de inserção no mercado de trabalho e, quando inseridas nesse contexto, recebem menos do que os homens, ocupando normalmente cargos hierarquicamente inferiores, conforme o Relatório Nacional de Acompanhamento dos Objetivos de Desenvolvimento do Milênio, do Governo Federal.

O presente artigo objetiva fundamentalmente confrontar a legislação atual com o estereótipo em desfavor das mulheres nas relações de emprego, incentivando a participação coletiva na conscientização em favor do rompimento de tais preconceitos que ainda se fazem presentes em nossa sociedade. Visando ainda, fornecer uma reflexão crítica-analítica sobre tal determinante, e levando ao leitor o conhecimento sobre as políticas públicas empregadas na efetivação destes propósitos.

O método utilizado para atingir os objetivos estabelecidos neste estudo será o analítico dedutivo, buscando esclarecer conceitos, elucidar proposições, partindo de uma ampla pesquisa bibliografia sobre o tema. Para a concretização das intenções do método analítico, os procedimentos usados deverão ser o da pesquisa bibliográfica por meio de textos legais, doutrinários, livros e artigos relacionados à temática.

Diante do exposto, pretende-se analisar os institutos de proteção da mulher no que tange a igualdade de gênero e inserção no mercado de trabalho, tendo como alicerce estudos já elaborados sobre o tema, bem como o posicionamento de doutrinadores pátrios, sob a ótica da Constituição Federal e da Consolidação das Leis do Trabalho - CLT.

3 O texto Constitucional citado sintetiza os dois primeiros artigos da Declaração Universal dos Direitos Humanos (de 10 de dezembro de 1948), a qual o Brasil é signatário. 


\section{Igualdade em Foco}

Hodiernamente, tem-se como tema de grande relevância o preceito de igualdade nos mais variados campos de aplicação. Ordem que tange a esfera Democrática dos Estados, que faz dos ideais encabeçados na Revolução Francesa em 1789: liberdade, igualdade $e$ fraternidade, e ainda, cem anos antes, na Inglaterra, com a Declaração dos Direitos do Cidadão $^{4}$, como um princípio fundamental a ser seguido e regulado.

O substantivo igualdade, que deriva do latim aequalitate, tem seu significado, conforme Ferreira (1986, p. 915), uma "qualidade ou estado de igual; paridade; uniformidade; identidade; justiça; propriedade de ser igual", significado esse que traduz as normas constitucional e infraconstitucionalmente expressas.

A igualdade, nota-se, é um direito que vem sendo almejado durante os últimos séculos, mas que segundo Léa Elisa Silingowschi Calil (2009, p. 01), em oportuna abordagem sobre o tema, aduz: "O século passado - o século XX - foi o século da igualdade. Desde suas primeiras décadas, houve movimentos pelo reconhecimento da igualdade entre homens e mulheres [...]", para tanto que o ordenamento jurídico brasileiro já consagrava nas Cartas de 1824 no tempo do Império e 1891, já como Estado independente, tal princípio, assim como em todo o decorrer histórico constitucional ${ }^{5}$ que se estende ao longo do século $\mathrm{XX}$, com singular propriedade na Constituição de 1988, que dá ênfase a um conceito mais protecionista, antagônico a quaisquer formas de discriminação e preconceito, elencado como pilar no Estado democrático de Direito.

O ordenamento constitucional vigente expressa desde o Preâmbulo o repúdio ao preconceito, prescrevendo logo no Art. $3^{\circ}$, inciso IV, como um dos objetivos fundamentais da

4 Conhecido também como Bill of Rigths.

$5 \quad$ Constituição Política do Império do Brasil, de 25.03.1824: "Art. 179, XIII. A lei será igual para todos, quer proteja, quer castigue, e recompensará em proporção dos merecimentos de cada um".

Constituição da República dos Estados Unidos do Brasil, de 24.02.1891: "Art. 72, §2. Todos são iguaes perante a lei. A Republica não admitte privilegio de nascimento, desconhece foros de nobreza, extingue as ordens honoríficas existentes e todas as suas prerrogativas e regalias, bem como os títulos nobiliarchicos e de conselho".

Constituição da República dos Estados Unidos do Brasil, de 16.07.1934: “Art. 113, 1. Todos são iguaes perante a lei. Não haverá privilégios, nem distincções, por motivo de nascimento, sexo, raça, profissões proprias ou dos paes, classe social, riqueza, crenças religiosas ou ideas políticas".

Constituição dos Estados Unidos do Brasil, de 10.11.1937: “Art. 122, 2. Todos são iguais perante a lei”. lei”.

Constituição dos Estados Unidos do Brasil, de 18.09.1946: “Art. 141, §1. Todos são iguais perante a

Constituição do Brasil, de 24.01.1967: “Art. 150, §1. Todos são iguais perante a lei, sem distinção de sexo, raça, trabalho, credo religioso e convicções políticas. O preconceito de raça será punido pela lei”.

Constituição da República Federativa do Brasil, de 17.10.1969: “Art. 153, §1 ${ }^{\circ}$. Todos são iguais perante a lei, sem distinção de sexo, raça, trabalho, credo religioso e convicções políticas. Será punido pela lei o preconceito de raça". 
República Federativa do Brasil a promoção do bem de todos, sem preconceitos ou qualquer outra forma de discriminação. O Art. $4^{\circ}$, VIII, expõe o repúdio ao racismo (tratando neste artigo quanto à regência nas relações internacionais). O Art. $5^{\circ}, \mathrm{XLI}$, assinala que a lei punirá qualquer forma de discriminação atentatória dos direitos e garantias fundamentais; e o mesmo artigo, no inciso XLII, expressa como crime inafiançável e imprescritível a prática de racismo. Finalmente, o Art. $7^{\circ}, \mathrm{XXX}$, trata da proibição de diferença salarial, de exercício de funções e de critérios de admissão, também por motivo de sexo.

Em todo este processo positivado em busca do tratamento isonômico, é fundamental citar que tal princípio não é absoluto. Vicente Paulo (2004, p.64), em opúsculo organizado por Maia, trata singularmente sobre o tema:

O princípio constitucional da igualdade não veda que a lei estabeleça tratamento diferenciado entre pessoas que guardem distinções de grupo social, de sexo, de profissão, [...]; não se admite é que o parâmetro diferenciador seja arbitrário, desprovido de razoabilidade, ou deixe de atender a alguma relevante razão de interesse público. (nosso grifo)

Ao se tratar desta matéria, observa-se que surge um limite à inviolabilidade de direitos, porém, ao transcender tal barreira, a justificativa deve ser plausível, tendo por fundamento um bem comum, com o objetivo de alcançar certo desígnio. Neste liame, cabe citar a título de exemplificação, a proteção especial da mulher gestante, que obtêm estabilidade no exercício do trabalho (salvo em caso de celebração de contrato por prazo determinado) e ainda o salário maternidade o qual tem direito. $\mathrm{O}$ exemplo citado trata de matéria singular às mulheres na qualidade especial de gestante, tratando com disparidade da mulher não gestante e dos trabalhadores do sexo masculino. Este tratamento desigual denota a transcendência na esfera da isonomia, porém sem violar a barreira do aceitável, mostrando consonância ao princípio da igualdade, pois como supracitado esta proteção está voltada à qualidade especial da mulher grávida.

Quanto a este assunto, Moraes (2008, p.36) salienta:

Dessa forma, o que se veda são as diferenciações arbitrárias, as discriminações absurdas, pois, o tratamento desigual dos casos desiguais, na medida em que se desigualam, é exigência tradicional do próprio conceito de Justiça, pois o que realmente protege são certas finalidades, somente se tendo por lesado o princípio constitucional quando o elemento discriminador não se encontra a serviço de uma finalidade acolhida pelo direito [...].

O ordenamento jurídico, então, coloca limitações ao legislador, que no caso da edição de normas que tragam abuso e arbitrariedade, sem qualquer conotação aceita, entrarão em choque com a Constituição Federal, tornando-se assim, inconstitucionais. 
Completando a inteligência delineada, Celso Antônio Bandeira de Mello (1993, p. 7983), aduz:

\begin{abstract}
Em verdade, o que se tem de indagar para concluir se uma norma desatende a igualdade ou se convive bem com ela é o seguinte: se o tratamento diverso outorgado a uns for 'justificável', por existir uma 'correlação lógica' entre o 'fator de discrímen' tomado em conta e o regramento que se lhe deu, a norma ou conduta são compatíveis com o princípio da igualdade; se, pelo contrário, inexistir esta relação de congruência lógica ou - o que ainda seria mais flagrante - se nem ao menos houvesse fatos de discrímen identificável, a norma ou conduta serão incompatíveis com o princípio da igualdade.
\end{abstract}

O legislador tem adentrado na esfera de protecionismo a igualdade, demonstrando que todos os cidadãos têm o direito de tratamento isonômico perante a lei.

Nesta acepção normativa, após este intróito sobre o entendimento de igualdade, buscase ainda elucidar algumas questões acerca do panorama da educação feminina, e em seguida, a ótica constitucional e da legislação específica do direito do trabalho, que regulamentam o trabalho da mulher e buscar esclarecer os fatores que levam a existência dos estereótipos nas relações trabalhistas.

\title{
3. O Panorama da Educação Feminina e a Inclusão da Mulher no Mercado de Trabalho
}

O terceiro relatório dos Objetivos de Desenvolvimento do Milênio, publicado em setembro de 2007 pelo Instituto de Pesquisa Econômica Aplicada e Secretaria de Planejamento e Investimentos Estratégicos do Governo Federal, tem elencado como o objetivo de número três, a promoção da igualdade entre os sexos e a autonomia das mulheres. Uma das análises feitas enfoca a predominância das mulheres no nível de educação superior. Porém, apesar desta preponderância feminina, importante se faz buscar subsídios que justifiquem o fato das mulheres ainda receberem menos do que os homens.

O relatório do IPEA (2007, p. 52), expressa que "a população feminina tem maior acesso à educação nos três níveis de ensino", e ainda que em relação ao nível superior essa diferença é de $31 \%$. Percebe-se ainda que muitos jovens do sexo masculino, devido às condições de vida, tentam conciliar o ensino superior com o trabalho, o que acarreta muitas vezes à desistência dos estudos. Em contrapartida, as meninas, "devido aos estereótipos de gênero vigentes, acabam assumindo os afazeres domésticos, e com isso tem maior possibilidade de conciliar o trabalho, em casa, com as atividades escolares - o que lhes permitem permanecer mais anos na escola" (IPEA, 2007, p.53). Estes parâmetros servem como subsídio para explicar o fato das mulheres predominarem nas universidades, conforme o percentual apresentado. 
As pesquisas realizadas pelo IPEA (2007, p.53) buscam elucidar ainda a relevante diferença salarial entre homem e mulher. Abordando a questão da seguinte maneira:

\begin{abstract}
A separação das carreiras reflete, em larga medida, a própria divisão sexual do trabalho - traduzindo-se em "carreiras femininas", mais vinculadas às áreas sociais, portanto de "cuidado", e as carreiras "masculinas", identificadas com as ciências exatas, mais técnicas. A essa separação corresponde uma divisão em termos de hierarquia e reconhecimento social e salarial: enquanto as áreas ditas "femininas" acabam constituindo-se nas carreiras menos valorizadas socialmente, aquelas ocupadas em sua maioria por homens revelam-se espaços com maior remuneração e prestígio social.
\end{abstract}

Logicamente que não podem ser analisados tais resultados lato sensu, e sim como indicadores que tentam explicar a disparidade no que tange as margens salariais entre os sexos. Salienta Sérgio Pinto Martins (2000), que os preconceitos em relação à mulher são oriundos de uma sociedade paternalista, que enxerga o pai como chefe de família, devendo este ser o único arrimo financeiro da família.

Analisando os percentuais de empregados com carteira assinada, os números apontados pelo Instituto de Pesquisas Econômicas, dão conta que os empregados do sexo masculino chegam a 35,0\% com carteira assinada, e as mulheres apenas 26,7\%. É uma margem de diferença relativamente alta, vindo a ser reflexo do elevado número de trabalhadoras domésticas.

Na mesma acepção, o Instituto Brasileiro de Geografia e Estatística - IBGE, divulgou um estudo compreendendo o período entre janeiro de 2003 e 2008 analisando a distribuição entre as atividades econômicas das mulheres ${ }^{6}$. Foi verificado que $16,5 \%$ estavam nos Serviços Domésticos; 22,0\% na Administração Pública, Educação, Defesa, Segurança e Saúde; 13,3\% em Serviços prestados à Empresa; $13,1 \%$ na Indústria; $0,6 \%$ na Construção, $17,4 \%$ no Comércio e 17,0\% em Outros Serviços e Outras Atividades. Em comparativo, a participação masculina predomina na indústria, em que chega à margem de 20,0\%, e diferentemente das mulheres, eles têm um maior percentual de ocupação na construção, 12,0\% e menor presença nos Serviços Domésticos, 0,7\%.

Com base nos dados expostos vem à tona a questão do trabalho doméstico em que quase $17 \%$ de empregabilidade é da mulher. Porém, segundo o IPEA, desse percentual, cerca de três quartos não têm registro em carteira (2007. p. 56). Analisa-se que tais dados mostram

\footnotetext{
6 A Pesquisa Mensal de Emprego - PME - implantada em 1980, produz indicadores para o acompanhamento conjuntural do mercado de trabalho nas regiões metropolitanas de Recife, Salvador, Belo Horizonte, Rio de Janeiro, São Paulo e Porto Alegre. Trata-se de uma pesquisa domiciliar urbana realizada através de uma amostra probabilística, planejada de forma a garantir os resultados para os níveis geográficos em que é produzida. (fonte: IBGE)
} 
uma alarmante realidade, se levado em conta que o trabalho sem carteira assinada não oferece proteção alguma no que tange aos benefícios sociais e previdenciários devidos ao trabalhador.

Vale transpor ainda, as assertivas doutrinárias de Martins (2000, p. 537), o qual lembra que "no anúncio ao emprego não se poderá fazer discriminação quanto a sexo, cor ou idade, para a admissão, salvo quando a natureza da atividade seja notória e publicamente incompatível”. Nessa esfera, o IPEA (2007, p.57) relata:

O grande número de trabalhadoras domésticas e a elevada proporção das que não
possuem carteira de trabalho talvez representem o lado mais evidente da
precariedade do trabalho feminino. O trabalho doméstico é uma ocupação que
remunera mal, exige muito em termos de carga horária e esforço físico e traz poucas
garantias no que diz respeito à segurança para o futuro - devido aos baixos níveis de
proteção social. Em 2004 , as trabalhadoras domésticas recebiam, em média, R\$
14,32 por dia trabalhado, contraposto aos valores de $\mathrm{R} \$ 32,72$ de rendimento-dia da
população em geral.

Mais uma vez os dados da pesquisa mostram que mesmo a mulher sendo mais escolarizada, continua recebendo menos do que os homens, principalmente em virtude da questão da inserção consideravelmente maior da mulher no mercado de trabalho doméstico, motivo que leva a identificar que está atrelado aos estereótipos de gênero.

Quando é tratado o tema em relação ao mesmo ramo de atividade e grau de escolaridade elevado, aparece uma nova determinante em que a discriminação contras as mulheres fica evidente. Nos "postos de trabalho de mais alta escolaridade, a discriminação e a divisão de carreiras entre homens e mulheres acabam restringindo o acesso das trabalhadoras às ocupações mais valorizadas e aos postos de hierarquia elevada" (IPEA, 2007, p.59). Esta situação demonstra que o número de anos de estudos tem influência direta nos rendimentos e cargos ocupados, trazendo assim uma disparidade nos níveis de renda dos dois grupos, colocando o homem com predominância hierárquica.

Oportunamente, Martins (2000, p. 261), abordando sobre o tema declara:

A Declaração Universal dos Direitos do Homem, de 1948, no art. 23, n. ${ }^{\circ} 2$, também esclarece que "toda pessoa tem direito, sem nenhuma discriminação, a um salário igual para um trabalho igual". O Pacto Internacional de Direitos Econômicos, Sociais e Culturais, de 1966, estabelece em seu art. $7 .^{\circ}$ que os trabalhadores têm o direito a um salário eqüitativo e igual por trabalho de igual valor, sem nenhuma distinção, inclusive quanto ao trabalho da mulher em relação ao do homem.

A Organização Internacional do Trabalho repudia expressamente a discriminação no emprego e na ocupação, por meio da Convenção $n^{\circ} 111$, editada em 4 de junho de 1958 e ratificada pelo Brasil em 19 de janeiro de 1968 pelo Decreto $N^{\circ} 62.150$ que em seu Artigo $1^{\circ}$, n.1, aduz: 
Para os fins desta Convenção, o termo "discriminação" inclui:

a) toda distinção, exclusão ou preferência, feita com base em raça, cor, sexo, religião, opinião política, ascendência nacional ou origem social, que tenha por efeito anular ou impedir a igualdade de oportunidades ou de tratamento no emprego ou na ocupação;

b) qualquer outra distinção, exclusão ou preferência que tenha por efeito anular ou impedir a igualdade de oportunidades ou tratamento no emprego ou na ocupação, conforme pode ser definido pelo Membro em questão, após consultar organizações representativas de empregadores e de trabalhadores, se as houver, e outros organismos convenientes ${ }^{7}$.

O Ministério do Trabalho e Emprego faz menção aos atos discriminatórios em um contexto geral e suas consequências:

A discriminação reduz o acesso às oportunidades de trabalho, emprego, renda, qualificação, educação, saúde e a outros direitos essenciais à cidadania. Ao ser combatida, devem-se levar em conta as dimensões de gênero, etnia, raça, geração, escolaridade, orientação sexual e deficiência que, apesar de não esgotarem a questão da discriminação, são os focos de grandes desigualdades no mundo do trabalho. (nosso grifo).

A discriminação à mulher não vem a ser um problema exclusivamente feminino, pois de acordo com Calil (2007), há uma supressão nos direitos constitucionalmente consagrados, negando o direito à igualdade, gerando menos avanços sociais, diminuindo o crescimento econômico, agravando os males sociais. É comprovado que a discriminação à mulher no mundo do trabalho causa um prejuízo à toda a sociedade, e as ações de combate devem ser constantes a fim de recepcionar as Proteções Antidiscriminatórias que se tornaram evidentes como anteriormente citado com o novo Texto Constitucional de 1988, o qual será tratado com maior ênfase no tópico que segue.

\section{Proteção ao Trabalho da Mulher: abordagem sob a ótica da legislação}

Preceitua o Art. 5, inciso I da Constituição Federal de 1988 que "homens e mulheres são iguais em direitos e obrigações", em seguida no Art. $7^{\circ}$ inciso XX, cita a operacionalidade da "proteção do mercado de trabalho da mulher, mediante incentivos específicos" e, conforme o inciso XXX do mesmo artigo é proibido "a diferença de salários, de exercício de função e de critério de admissão por motivo de sexo, idade, cor ou estrado civil”. Considera-se, portanto, a colocação de Almeida (2007) que lembra que haverá inconstitucionalidade em toda e qualquer restrição ao trabalho da mulher, com exceção às vedações impostas propriamente devido a sua natureza, como é o caso da licença-maternidade.

7 A Convenção N. 111 da OIT está disponível na íntegra e com a grafia original na Página Eletrônica: http://www6.senado.gov.br/legislacao/ListaTextoIntegral.action?id=92814 
Nesta mesma linha de entendimento, em 12 de outubro de 1988, o Ministério do Trabalho editou a Instrução Normativa $n^{o} 1$, publicada no Diário Oficial da União em 21 de outubro do mesmo ano, a qual possui os seguintes termos:

O artigo $5^{\circ}$ da Constituição Federal preceitua que todos são iguais perante a lei e que
não deve haver distinções de qualquer natureza.
Por outro lado, o inciso I do referido artigo preconiza que "homem e mulher são
iguais em direitos e obrigações", sendo que o inciso XXX, do art. $7^{\circ}$, proíbe a
diferença de exercício de funções, de critério de admissão e de salários, por motivo
de sexo.
Face a esses dispositivos constitucionais, não cabe ao Poder Executivo, em especial
ao Ministério do Trabalho, criar restrições ao trabalho da mulher.
Assim, no que concerne à jornada, seja quanto a hora extra ou compensação de
horas, seja quanto ao trabalho noturno, aplicam-se à mulher os dispositivos que
regulam o trabalho masculino.

Note-se a significativa atenção do legislador constitucional no tocante à situação da mulher trabalhadora, que foi ensejando várias alterações nos textos infraconstitucionais e a criação de leis tratando do assunto. Para tanto que em 1989, com a promulgação da Lei $n^{\circ}$. 7.855 (DOU, 29-10-1989), revogaram-se vários artigos da CLT que tratavam sobre impedimentos ao trabalho da mulher com referencia claramente discriminatória. Ressalta-se que a incompatibilidade de qualquer preceito com a Carta Maior invalida sua eficácia, não tendo aplicação por ser passível de inconstitucionalidade.

Posteriormente, merecem destaque as Leis $n^{\circ} .9 .029 / 95$ e 9.799/99, que acentuam o combate a discriminação do trabalho feminino.

A primeira pró́be a "adoção de qualquer prática discriminatória e limitativa para efeito de acesso à relação de emprego, ou sua manutenção, por motivo de sexo, origem, raça, cor, estado civil, situação familiar ou idade" (Art. $1^{\circ}$ da Lei $n^{\circ} 9.029 / 95$ ). O artigo $2^{\circ}$ da referida lei, aduz como ato discriminatório a exigência de declarações, exames e medidas congêneres relativamente à esterilização ou estado de gravidez. Veda a indução ao controle de natalidade, salvo o "oferecimento de serviços de aconselhamento ou planejamento familiar, realizado através de instituições públicas ou privado, submetidas às normas do Sistema Único de Saúde - SUS" (Art. 2, Lei no 9.029/95). Aduz, ainda, em seu Art. 4º que o "rompimento da relação de trabalho por ato discriminatório, nos moldes tipificados na lei, faculta o empregado optar entre duas alternativas reparatórias", fornecendo à trabalhadora, formas optativas de garantia de direitos: "a readmissão com ressarcimento integral de todo o período de afastamento, mediante pagamento das remunerações devidas, corrigidas monetariamente, acrescidas dos juros legais", entendendo que a reintegração deve ser imediata; e "a percepção, em dobro, da remuneração do período de afastamento, corrigida monetariamente e acrescida 
dos juros legais", obviamente, neste caso, a trabalhadora não terá direito ao retorno ao cargo anteriormente ocupado.

Por sua vez, a Lei $n^{\circ}$ 9.799, inseriu na Consolidação das Leis do Trabalho, determinadas regras sobre o acesso da mulher ao mercado de trabalho. Tornando expressos, conforme lembrado por Delgado (2008) os parâmetros contra a discriminação.

Esta Lei, datada de 26.05.1999, acrescenta na CLT o Art. 373-A que se apresenta de suma importância, vedando uma série de ações que direta ou indiretamente vem a criar distorções que afetam o acesso da mulher ao mercado de trabalho. É merecedor de especial atenção o Parágrafo Único do dispositivo citado, o qual dispõe que o conteúdo do artigo "não obsta a adoção de medidas temporárias que visem ao estabelecimento das políticas de igualdade entre homens e mulheres, em particular as que se destinam a corrigir as distorções que afetam a formação profissional, o acesso ao emprego e as condições gerais de trabalho da mulher".

Nota-se que a ênfase determinada pelas duas Leis apresentadas, reforça muito e tornam incontestes os parâmetros de vedação e diferenciação no âmbito do trabalho, passando a lei, a tratar o trabalho da mulher com igualdade ${ }^{8}$ em relação ao homem.

Torna-se fundamental abordar como forma de dar termo ao presente estudo, as principais proteções da Lei ao trabalho da mulher:

a) Duração da jornada de trabalho da mulher:

A jornada de trabalho da mulher é igualmente de oito horas diárias e quarenta e quatro horas semanais (artigo $7^{\circ}$, XIII da Constituição Federal), podendo a mulher fazer horas extraordinárias nas mesmas condições do que o homem visto a revogação do artigo 376 da CLT pela Lei $\mathrm{n}^{\circ}$ 10.244/01. O trabalho extraordinário, com exceção ao sistema compensatório, deverá ser remunerado com adicional de 50\% (artigo $7^{\circ}, \mathrm{XVI}, \mathrm{CF}$ ).

b) Trabalho noturno, insalubre e perigoso:

Com a proclamação da igualdade entre homem e mulher, não há proibição alguma do trabalho insalubre ou de perigo. Não existe ainda, qualquer restrição ao trabalho à noite da mulher (salvo se for menos de dezoito anos), desde que sejam observados a redução de hora e o pagamento do adicional respectivo por trabalho noturno (Almeida, 2007), que é de $20 \%$ sobre a hora diurna, sendo reduzida a hora noturna de 60 minutos para 52 minutos e trinta segundos.

8 Exceto, novamente citando, quando a lei deva fornecer tratamento diferenciado a fim de proteger a própria natureza feminina. 
c) Licença-maternidade:

Merece determinada atenção ao tratar sobre o tema. A Constituição Federal de 1988 preceitua no Art. $7^{\circ}$, XVII que haverá "licença à gestante, sem prejuízo do emprego e do salário, com duração de cento e vinte dias". O dispositivo alterou o prazo anteriormente de 84 dias que era estipulado pela $\mathrm{CLT}^{9}$. A licença maternidade, à gestante, é possível de ser prorrogado por mais dois meses conforme a Lei $n^{\circ}$. 11.770/08. Neste contexto, a Lei prevê que durante a prorrogação da licença-maternidade a empregada terá direito à remuneração integral. Os dois meses adicionais de licença serão concedidos imediatamente após o período de 120 dias previsto na Constituição. No período de prorrogação da licença a empregada não poderá exercer qualquer atividade remunerada e a criança não poderá ser mantida em creche ou organização similar (Art. $4^{\circ}$ ). A Lei presume também incentivos fiscais às empresas que aderirem o aumento do prazo de licença à gestante.

d) Licença-maternidade à mãe adotiva:

A Lei $\mathrm{n}^{\circ}$. 10.421/02 acrescentou à CLT o Art. 392-A e parágrafos, estendendo a licença maternidade à empregada que adotar ou obtiver a guarda judicial de crianças, na seguinte proporção, conforme sintetizado por Almeida (2007, p. 160): "I- criança até um ano, licença de cento e vinte dias; II- a partir de um ano até quatro anos, licença de sessenta dias; III- de quatro até oito anos, licença de trinta dias". A licença maternidade à mãe adotiva é condicionada à apresentação de termo judicial.

e) Estabilidade da gestante:

O Art. 10, II, b, das Disposições Constitucionais Transitórias, instituiu a estabilidade à gestante:

Art. 10. Até que seja promulgada a lei complementar a que se refere o Art. $7^{\circ}$, I, da Constituição:

(...)

II- fica vedada a dispensa arbitrária ou sem justa causa: (...)

b) da empregada gestante, desde a confirmação da gravidez até cinco meses após o parto.

A empregada gestante não pode ser dispensada, salvo na ocorrência de justa causa (Art. 482 da CLT), e, quando se tratar de trabalho prejudicial à saúde da gestante, o Art. 394 da CLT faculta a rescisão do contrato de trabalho pela mulher, tratando ainda o Art. 487, § $2^{\circ}$ da CLT que não haverá a necessidade de aviso prévio ou descontos do salário.

f) Período de descanso:

9 Ressalta-se que a Consolidação das Leis do Trabalho não é um Código, e sim, um compilado de leis, reunidas e consolidadas pelo Decreto-Lei ${ }^{\circ} .5 .452$, de $1^{\circ}$ de maio de 1943. 
Trata a CLT que entre duas jornadas de trabalho deverá haver um intervalo mínimo de 11 horas para repouso (Art. 382). Aduz o Art. 383 do referido Diploma que "durante a jornada de trabalho será concedido à empregada um período para refeição e repouso não inferior a 1 (uma) hora nem superior a 2 (duas) horas". Já o Art. 384 da CLT prevê que haverá um descanso de no mínimo 15 minutos antes do começo de hora extraordinária.

g) Trabalhos proibidos:

A Lei n. ${ }^{\circ} 7.855 / 89$ revogou o Art. 387 da CLT que proibia o trabalho em "subterrâneos, minerações em subsolo, pedreiras e obras de construção pública e particular", e em "locais perigosos, insalubres ou penosos". Torna-se proibido o emprego de mulher em trabalho que "demande emprego de força muscular superior a 20 quilos em trabalho contínuo, ou 25 quilos para ocasional" (Art. 390, CLT). No que tange ao trabalho por "impulsão ou tração de vagonetes sobre trilhos, de carros de mão ou quaisquer aparelhos mecânicos" (artigo 390, § único, CLT), não há qualquer vedação expressa na legislação vigente.

h) Local e métodos de trabalho:

Dispões a legislação (Art. 389, CLT) que todas as empresas são obrigadas "a prover os estabelecimentos de medidas concernentes à higienização dos métodos e locais de trabalho, tais como ventilação e iluminação e outros que se fizerem necessários à segurança e ao conforto das mulheres [...]". Cita-se também o inciso segundo que obriga as empresas a “instalar bebedouros, lavatórios, aparelhos sanitários" além "de dispor de cadeiras ou bancos, em número suficiente, que permitam às mulheres trabalhar sem grande esgotamento físico". $\mathrm{O}$ mesmo artigo exige a instalação de vestiários com armários individuais e privativos para as mulheres, salvo em empregos que não seja exigido a troca de roupa (inciso III). Devem ainda ser fornecidos gratuitamente os equipamentos de proteção individual (E.P.I) às trabalhadoras, “tais como óculos, máscaras, luvas e roupas especiais, para a defesa dos olhos, do aparelho respiratório e da pele, de acordo com a natureza do trabalho" (inciso IV). Estas disposições legais regulamentam a manutenção do trabalho feminino, a fim de que o mesmo seja realizado com segurança e de forma digna.

\section{Considerações Finais}

Na presente pesquisa, foram abordados a priori o conceito de igualdade e o panorama educacional da mulher como uma forma de comparação aos números de pesquisas de 
emprego do Governo Federal identificando as deficiências na inclusão da mulher no mercado de trabalho.

Analisou-se que no Brasil, as Constituições Federais em toda a trajetória histórica abordou preceitos de igualdade em seus textos Magnos, ressaltando que a Constituição de 1988 adentrou na esfera de protecionismo à igualdade com maior ênfase, ressaltando que todos os cidadãos têm o direito de tratamento isonômico perante a lei.

Foi demonstrado que apesar do fato que a população feminina tem maior acesso à educação nos três níveis de ensino, principalmente no superior, há um estereótipo nas relações de trabalho ocasionando um reflexo negativo nas margens salariais das trabalhadoras. $\mathrm{Na}$ explicação desse discrímen, foi usado fundamentalmente o relatório do Instituto de Pesquisa Econômica Aplicada - IPEA. Na análise das carreiras escolhidas por homens e mulheres, identificou-se que a possível causa da diferença salarial está atrelada ao fato de as mulheres se dedicarem as áreas sociais, que em tese fornece menor remuneração e menor prestígio social.

Discorreu-se ainda sobre a precariedade do trabalho doméstico principalmente pela existência de um elevado número de trabalhadoras domésticas que não possuem carteira assinada, ou seja, sem a mínima proteção previdenciária.

As abordagens primárias trouxeram à tona a necessidade de abordar os fatos discriminatórios existentes nas relações de trabalho e que vem sendo por muitos anos combatidos por mecanismos internacionais e nacionais através de convenções (como é o caso da Convenção $n^{\circ} 110$ e 111 da OIT), estudos, secretarias, programas próprios e incentivos fiscais, como por exemplo, a prorrogação da licença maternidade. Fez-se notória a adequação do legislador constitucional no tocante à situação da mulher trabalhadora, que foi ensejando várias alterações nos textos infraconstitucionais e a criação de leis tratando do assunto, com destaque para as Leis $n^{\circ}$. 9.029/95 e 9.799/99.

Finalmente foi concluída a pesquisa, expondo à luz da Consolidação das Leis do Trabalho e da Constituição Federal de 1988, os principais preceitos legais de proteção à mulher no âmbito do trabalho.

A pesquisa buscou, sobretudo, mostrar um panorama do trabalho feminino, abordando de forma estrita e programática os conteúdos, desenvolvendo um plano linear de idéias explicativas regulamentadas pela legislação, expondo a fruição dos relacionamentos trabalhistas de forma a construir um instituto de conscientização, demonstrando a importância da ação Estatal na proteção do trabalho feminino na constante busca da superação dos estereótipos. 


\section{REFERÊNCIAS}

AGÊNCIA BRASIL. Mulheres são maioria nas universidades, mas têm menos espaço no mercado de trabalho. Disponível em: $\quad<$ http://www.agenciabrasil.gov.br/noticias/2007/08/29/materia.2007-0829.6965420720/view>. Acesso em: 12. Out. 2009.

ALMEIDA, Amador Paes de. CLT comentada: legislação, doutrina, jurisprudência. - 4. ed. rev., atual. e ampl. - São Paulo: Saraiva, 2007.

BRASIL. Constituição da República Federativa do Brasil de 1988. São Paulo, Saraiva, 2009.

CALIL, Léa Elisa Silingowschi. Direito do Trabalho da mulher: a questão da igualdade jurídica ante a desigualdade fática. $1^{\mathrm{a}}$ Edição. São Paulo: LTR, 2007.

CALIL, Léa Elisa Silingowschi. Liberdade, Igualdade e Fraternidade. Disponível em: <http://www.mundodosfilosofos.com.br/lea4.htm>. Acesso em: 10. Out. 2009.

DELGADO, Maurício Godinho. Curso de direito do trabalho. - 7 a ed.. - São Paulo: LTr, 2008.

FERREIRA, Aurélio Buarque de Holanda. Novo dicionário Aurélio da língua portuguesa. 3. ed. Rio de Janeiro: Nova Fronteira, 1986.

INSTITUTO BRASILEIRO DE GEOGRAFIA E ESTATÍSTICA. Pesquisa Mensal de Emprego. Algumas características da inserção das mulheres no mercado de trabalho. Disponível em: <http://www1.ibge.gov.br/home/estatistica/indicadores/trabalhoerendimento/pme mulher/Suplemento_Mulher 2008.pdf $>$ Acesso em: 17. Out. 2009.

INSTITUTO DE PESQUISA ECONÔMICA APLICADA. Objetivos de Desenvolvimento do Milênio. Relatório Nacional de Acompanhamento. Disponível em: <http://www.ipea.gov.br/sites/000/2/download/TerceiroRelatorioNacionalODM.pdf >. Acesso em: 10. Out. 2009.

LEI No 9.029, DE 13 DE ABRIL DE 1995. Proíbe a exigência de atestados de gravidez e esterilização, e outras práticas discriminatórias, para efeitos admissionais ou de permanência da relação jurídica de trabalho, e dá outras providências. Disponível em: < http://www.planalto.gov.br/ccivil_03/LEIS/L9029.htm>. Acesso em: 7. Nov. 2009.

LEI N 9.799, DE 26 DE MAIO DE 1999. Insere na Consolidação das Leis do Trabalho regras sobre o acesso da mulher ao mercado de trabalho e dá outras providências. Disponível em: < http://www.planalto.gov.br/ccivil/leis/L9799.htm>. Acesso em: 9. Out. 2009.

LEI N $N^{\circ} 11.770$, DE 9 DE SETEMBRO DE 2008. Cria o Programa Empresa Cidadã, destinado à prorrogação da licença-maternidade mediante concessão de incentivo fiscal, e altera a Lei no 8.212, de 24 de julho de 1991. Disponível em: < http://www.planalto.gov.br/ccivil 03/_Ato20072010/2008/Lei/L11770.htm>. Acesso em: 7. Nov. 2009.

MAIA, Juliana. Aulas de direito constitucional de Vicente Paulo / org. Juliana Maia. - $3^{\text {a }}$ Ed. - Rio de Janeiro: Impetus, 2004.

MARTINS, Sergio Pinto. Direito do Trabalho. 10ª ed. rev. e ampl. - São Paulo. Editora Atlas S.A., 2000.

MELLO, Celso Antonio Bandeira de. "Princípio da isonomia: desequiparações proibidas e desequiparações permitidas”. Revista Trimestral de Direito Público. São Paulo: Malheiros, 1993.

MINISTÉRIO DA JUSTIÇA. Declaração Universal dos Direitos Humanos. Disponível em: <http://www.mj.gov.br/sedh/ct/legis_intern/ddh_bib_inter_universal.htm>. Acesso em: 12. Out. 2009.

MINISTÉRIO DO TRABALHO E EMPREGO. Promoção de Igualdade de Oportunidades e de Combate à Discriminação no Trabalho. Disponível em: < http://www.mte.gov.br/discriminacao/PlanoInterno.pdf>. Acesso em: 8. Nov. 2009. 
MORAES, Alexandre de. Direito Constitucional. - 23. Ed. - São Paulo: Atlas, 2008.

REVISTA DE DIREITO. Constitucional e Internacional. Ano 10, n. 38. Ed. Revista dos Tribunais - janeiro março de 2002.

SENADO FEDERAL. Convenção no 111 da OIT sobre discriminação em matéria de emprego e profissão. Disponível em: < http://www6.senado.gov.br/legislacao/ListaTextoIntegral.action?id=92814>. Acesso em: 17. Out. 2009.

STF - Pleno - MS no 22.164/SP - Rel. Min. Celso de Mello, Diário da Justiça, Seção I, 17. Nov. 1995. 